www.jmscr.igmpublication.org

Impact Factor 5.84

Index Copernicus Value: 71.58

ISSN (e)-2347-176x ISSN (p) 2455-0450

crossref DOI:_https://dx.doi.org/10.18535/jmscr/v6i1.63

Journal Of Medical Science And Clinical Research

\title{
Our experience with subfascial perforator vein ligation by Cockett and Dodd in perforator incompetence of varicose veins
}

\author{
Authors \\ Dr Reny Jayaprakas ${ }^{1}$, Dr Vishal Raj ${ }^{2}$, Dr G. Ambujam ${ }^{3}$ \\ ${ }^{1}$ Asst Prof, VMMC, Karaikal \\ ${ }^{2}$ Post Graduate, VMMC, Karaikal \\ ${ }^{3}$ HOD and Professor, VMMC, Karaikal \\ Corresponding Author \\ Dr Reny Jayaprakas \\ Asst Prof, VMMC, Karaikal \\ Email:drrenyjp@gmail.com
}

\begin{abstract}
Aims and Objectives

1. To study the role of subfascial perforator vein ligation by Cockett and Dodd in perforator incompetence of varicose veins.

2. To study the complications following the procedure.

Materials and Methodology: prospective study was conducted in the period between August 2015 and August 2017 in the department of General Surgery in Vinayaka Missions Medical college, Karaikal. 32 cases of varicosities of the lower limbs with perforator incompetence with or without Saphenofemoral incompetence were included in the study.

Observation and Results: Our study had 20 males and 12 females. Commonest age group affected was 41 50 (43.25\%). The most common presentation of the patients was ulcers (56.25\%), followed by pain, skin changes etc. The left (53.1\%) side was more commonly involved, bilateral disease was noted in 2 cases (6\%). Perforator ligation alone was performed in 14 cases $(42.75 \%)$, whereas combined perforator ligation with stripping +/- Saphenopopliteal ligation was done in 18 cases(56.25\%). Post operatively shorter hospital stay was noted in the group with perforator ligation alone-average of 6.4 days, 9.3 days for the cases with combined procedure. Residual perforator incompetence was seen in 2 cases (6.25\%). Postoperative wound infection was seen in 2 cases (6.25\%). Delayed wound healing in 1case (3.12\%).

Conclusion: Open perforator ligation (Cockett and Dodd's) has been largely replaced by SEPS procedure in many centres around the world. But, open subfascial perforator ligation is a useful, effective procedure in treatment of patients with primary varicose veins with perforator incompetence, particularly in centres, which lack the facilities for endoscopic procedure.

Keywords: subfascial perforator ligation, perforator incompetence, varicose veins.
\end{abstract}

\section{Introduction}

Varicose veins are defined as dilated usually tortuous, subcutaneous veins $>3 \mathrm{~mm}$ in diameter measured in upright position with demonstrable reflux ${ }^{1}$. Varicose veins are part of the penalty we pay for the erect posture. Varicose veins affects $25-30 \%$ female population and $15 \%$ in men $^{1}$. There is variation in presentation of varicose 
veins, commonest of which being ulceration and pain which indicates how debilitating this condition is, if there is delay in seeking medical care $^{2}$.

Varicose veins have a significant socioeconomic impact in terms of medical care, work and reduced quality of life $^{3}$. There is a wide variation in healing and recurrence rates of these varicose veins and its complications in the Indian population due to differing nutritional status, availability of medical facilities and trained medical staff to diagnose and manage such conditions. We present our experience in treating varicose veins with subfascial perforator ligation of Cockett and Dodd, in a tertiary care hospital in Karaikal, a city in coastal India.

\section{Materials and Methods}

This prospective study was conducted in the period between August 2015 and August 2017 in the department of general surgery in Vinayaka Missions Medical college, Karaikal.32 cases of varicosities of the lower limbs with perforator incompetence with or without saphenofemoral incompetence were included in the study.

Exclusion criteria - Patients with varicose veins not having perforator vein incompetence (those with Saphenofemoral or Saphenopopliteal incompetence only) were not included in the study, Patients with deep venous thrombosis, patients with previous surgery of the affected limb, associated arterial insufficiency (ABPI $<0.8$ ), diabetic ulcers, pregnancy.

Detailed history and demographic data was collected, patients underwent complete general and local examination. Clinical tests done to locate sites of perforator / saphenofemoral junction incompetence.Ulcers were debrided and regular dressing done, till granulation tissue appeared. Routine blood investigations done. Duplex ultrasound was done to locate the incompetent perforator veins and marked preoperatively. All the patients underwent subfascial ligation of the perforator veins by Cockett and Dodd method, with or without stripping and flush ligation of saphenofemoral junction, saphenopopliteal junction.

Patients for followed up on day1, day 3, week 1,4, 12 postoperatively for the results and to look out for possible complications like - wound infection, hematoma, nerve injury, recurrence.

\section{Observations and Results}

Our study had 20 males and 12 females (table 1). The commonest age group affected in our study was 41- 50(43.25\%). The most common presentation of the patients was ulcers $(56.25 \%)$ and pain $(50 \%)$, followed by skin changes and edema (Table 3). The site more commonly involved was the left $(53.1 \%)$ side, bilateral disease was noted in 2 cases $(6 \%)$ (Table 4$)$.

Perforator ligation alone was performed in 14 cases $(42.75 \%)$, whereas combined perforator ligation with stripping +/- Saphenopopliteal ligation was done in 18 cases $(56.25 \%)$ (Table 5). Post operatively shorter hospital stay was noted in the group with perforator ligation alone- average of 6.3 days (Table 6). The complications noted in our study are depicted in table 7.Residual perforator incompetence was seen in 2 cases $(6.25 \%)$. Postoperative wound infection was seen in 2 cases $(6.25 \%)$. Delayed wound healing in 1 case $(3.12 \%)$.

Table 1 - sex distribution

\begin{tabular}{|l|c|c|}
\hline gender & Number of cases & Percentage (\%) \\
\hline Males & 20 & 62.5 \\
\hline Females & 12 & 37.5 \\
\hline Total & 32 & 100 \\
\hline
\end{tabular}

Table 2 - Age distribution

\begin{tabular}{|l|c|c|}
\hline Age group & Number & Percentage $(\%)$ \\
\hline $30-40$ & 10 & 31.25 \\
\hline $41-50$ & 14 & 43.75 \\
\hline $51-60$ & 06 & 18.75 \\
\hline$>60$ & 02 & 6.25 \\
\hline Total & 32 & 100 \\
\hline
\end{tabular}


Table 3 Clinical presentation

\begin{tabular}{|l|c|c|}
\hline Presentation & Number of cases & Percentage(\%) \\
\hline Venous ulcers & 18 & 56.25 \\
\hline Pain & 16 & 50 \\
\hline $\begin{array}{l}\text { Skin changes - eczema(itching), hyperpigmentation, } \\
\text { induration, lipodermatosclerosis }\end{array}$ & 14 & 43.75 \\
\hline Edema & 11 & 34.37 \\
\hline Others - cramps, bleeding, heaviness of legs & 10 & 31.25 \\
\hline
\end{tabular}

Table 4 Site involved

\begin{tabular}{|l|c|c|}
\hline Site & Number of cases & percentage \\
\hline Left side & 17 & 53.1 \\
\hline Right side & 13 & 40.6 \\
\hline Bilateral & 2 & 6.25 \\
\hline
\end{tabular}

Table 5 Procedure performed

\begin{tabular}{|l|c|c|}
\hline Procedure & Number of cases & Percentage (\%) \\
\hline Perforator ligation alone & 14 & 42.75 \\
\hline $\begin{array}{l}\text { Perforator ligation with stripping } \\
\text { +/- SP ligation }\end{array}$ & 18 & 56.25 \\
\hline
\end{tabular}

Table 6 Postoperative hospital stay

\begin{tabular}{|l|c|}
\hline Procedure done & Average Time in days \\
\hline Perforator ligation alone & 6.3 \\
\hline Perforator ligation with other procedures & 9.4 \\
\hline
\end{tabular}

Table 7 Post operative complications

\begin{tabular}{|l|c|c|}
\hline & Number of cases & Percentage \\
\hline Recurrence of varicosity & 2 & $6.25 \%$ \\
\hline Wound infection & 2 & $6.25 \%$ \\
\hline Recurrence of ulcers & 0 & 0 \\
\hline Delayed wound healing & 1 & $3.12 \%$ \\
\hline Others - hematoma, nerve injury & 0 & 0 \\
\hline
\end{tabular}

\section{Discussion}

Major proportion of varicose veins cases in this study and other studies were of the age group 4160 years, similar to other studies ${ }^{4,5}$. Greater proportion of cases were males, as also observed in other studies probably due to occupationally related risk factors ${ }^{5}$ Several other studies on the contrary found a female preponderance among cases $^{6,7}$. This male preponderance in our study could be because of social reasons due to which less number of women seek medical intervention for this problem. In this study left side involvement was seen more frequently, similar to other studies ${ }^{7,8}$. The venous drainage through the pelvis follows a more tortuous course in the left lower limb. This is because the right common iliac artery traverses over the left common iliac vein thus enhancing the risk over the left side thus enhancing the risk over the left side ${ }^{9}$. The most common presenting symptom in varicose veins in this study was ulceration in contrast to several studies which reported pain as more common ${ }^{7,10}$. Active ulcers which were infected and with slough were preoperatively managed with debridement and daily dressings till the infection came down and the ulcer floor was covered with healthy granulations, to reduce post operative risk of infection.

The patients with isolated perforator incompetence were treated with the Cockett and Dodd procedure whereas the patients with concomitant saphenofemoral incompetence underwent limited stripping operation in addition to subfascial ligation. The mean postoperative stay 
for patients undergoing Cockett and Dodd procedure alone was 6.4 days and for patients who underwent perforator ligation with concomitant stripping procedure was 9.3 days. A study by Stuart et al reported an average hospital stay of 9 days for patients undergoing open perforator ligation ${ }^{11}$.Residual perforator incompetence was seen in 2 cases $(6.25 \%)$ of the total patients operated. In both the cases, the postoperative duplex scan showed incompetent perforators, indicating that they were the ones that were missed during surgery. Postoperative wound infection in our study was seen in 2 cases $(6.25 \%)$. Delayed wound healing without infection was seen in 1case $(3.12 \%)$. Lipodermatosclerosis, excema, could be the factors delaying wound healing in the case. Our wound infection rate is much lower to that of Bowen et al, who reported a $44 \%$ wound infection rate in patients undergoing open perforator surgery in a randomized trial comparing Cockett and Dodd procedure with SEPS. Wound hematoma was not noted in our study. Therefore, the results of SEPS are comparable to open perforator ligation, except for the risk of higher wound infection in the open procedure.

However, the surgical expertise, technical and economic requirements of SEPS, make it challenging for carrying out the procedures in all centres.

\section{Conclusion}

Open perforator ligation (Cockett and Dodd's) has been largely replaced by SEPS procedure in many centres around the world. But, Cockett and Dodd procedure of open subfascial perforator ligation is a useful procedure in treatment of patients with primary varicose veins with perforator incompetence, particularly in centres, which lack the facilities for endoscopic procedure. The complications of the procedure can be prevented by careful patient selection, careful operative technique and meticulous postoperative care.

\section{Bibliography}

1. Norman S.Williams, Christopher J.K Bulstrode, P. Ronan O’Connell. Bailey and Love's Short Practice of Surgery: Venous disorders. 26th ed. Boca Raton, London, New York: CRC Press; 2013.p 927-940.

2. Nithin Joseph et. Al. A multicenter review of epidemiology and management of varicose veins for national guidance. Annals of Medicine and Surgery, Volume 5, Supplement 1, January-December 2016, Pages S146.

3. X. Kurz, D.L. Lamping, S.R. Kahn, U. Baccaglini, F. Zuccarelli, G. Spreafico, L. Abenhaim. Do varicose veins affect quality of life? Results of an international population-based study. J. Vasc. Surg., 34 (2001), pp. 641-648

4. K. Das, S. Ahmed, S. Abro, M.S. Arain. Varicose veins; outcome of surgical management and recurrences. Prof. Med. J., 21 (2014), pp. 509-513.

5. E.M. Lins, J.W. Barros, F. Appolonio, E.C. Lima, M.B. Junior, E. Anacleto. Epidemiologic profile of patients who underwent varicose vein surgery of the lower limbs.J. Vasc. Bras., 11 (2012), pp. 301-304.

6. . Barandiaran, T. Hall, N. El-Barghouti, E. Perry. Day case management of varicose veins.Vasc. Surg. Princ. Pract. (2012)

7. N.L. Murli, I.D. Navin. Classical varicose vein surgery in a diverse ethnic community.Med. J. Malays., 63 (2008), pp. 193-198.

8. F.S. Barros, J.M.G. Perez, E. Zandonade. Evaluation of pelvic varicose veins using color Doppler ultrasound: comparison of results obtained with ultrasound of the lower limbs, transvaginal ultrasound and phlebography.J. Vasc. Bras., 9 (2010), pp. 15-23.

9. M.J. Callam. Epidemiology of varicose veins. Br. J. Surg., 81 (1994), pp. 167-17 
10. J. Saarinen, V. Suominen, M. Heikkinen, R. Saaristo, R. Zeitlin, J. Vainio, I. Nordback, J.P. Salenius. The profile of leg symptoms, clinical disability and reflux in legs with previously operated Varicose disease. Scand. J. Surg., 94 (2005), pp. 5155

11. Stuart WP, Asam DJ, Bradbury AW, Ruckley CV. Subfascial endoscopic perforator surgery is associated with significantly less morbidity and shorter hospital stay than open operation, $\mathrm{Br} \mathrm{J}$ Surg. 1997. 84: 1364-1365. 